\title{
Article \\ Antibacterial Activity of Cerium Oxide Nanoparticles against ESKAPE Pathogens
}

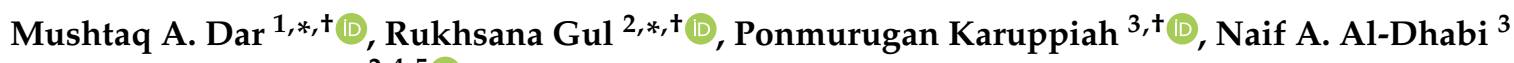 \\ and Assim A. Alfadda $2,4,5$ (D) \\ 1 Center of Excellence for Research in Engineering Materials (CEREM), College of Engineering, \\ King Saud University, Riyadh 11421, Saudi Arabia \\ 2 Obesity Research Center, College of Medicine, King Saud University, Riyadh 11461, Saudi Arabia; \\ aalfadda@ksu.edu.sa \\ 3 Department of Botany and Microbiology, College of Science, King Saud University, \\ Riyadh 11451, Saudi Arabia; pkaruppiah@ksu.edu.sa (P.K.); naldhabi@ksu.edu.sa (N.A.A.-D.) \\ 4 Department of Medicine, College of Medicine, King Saud University, \\ P.O. Box 2925, Riyadh 11461, Saudi Arabia \\ 5 Strategic Center for Diabetes Research, College of Medicine, King Saud University, \\ Riyadh 11461, Saudi Arabia \\ * Correspondence: mdar@ksu.edu.sa (M.A.D.); rgul@ksu.edu.sa (R.G.) \\ + These authors contributed equally to this work.
}

check for updates

Citation: Dar, M.A.; Gul, R.; Karuppiah, P.; Al-Dhabi, N.A.; Alfadda, A.A. Antibacterial Activity of Cerium Oxide Nanoparticles against ESKAPE Pathogens. Crystals 2022, 12, 179. https://doi.org/ $10.3390 /$ cryst12020179

Academic Editor: Jianying Huang

Received: 21 December 2021

Accepted: 22 January 2022

Published: 26 January 2022

Publisher's Note: MDPI stays neutral with regard to jurisdictional claims in published maps and institutional affiliations.

Copyright: () 2022 by the authors Licensee MDPI, Basel, Switzerland. This article is an open access article distributed under the terms and conditions of the Creative Commons Attribution (CC BY) license (https:// creativecommons.org/licenses/by/ $4.0 /)$.

\begin{abstract}
We studied the antimicrobial characteristics of cerium oxide $\left(\mathrm{CeO}_{2}\right)$ nanoparticles synthesized by hydrothermal technique. The versatile characterization techniques were employed to study the $\mathrm{CeO}_{2}$ nanoparticle structural and optical properties. These techniques included field emission scanning electron microscopy, Raman spectroscopy, X-ray diffraction, and transmission electron microscopy. The X-ray diffraction and Raman studies validated the cubic structure of the synthesized $\mathrm{CeO}_{2}$ nanoparticles with average diameters $\sim 3-5 \mathrm{~nm}$. The antibacterial activities and minimal inhibition concentrations (MICs) of $\mathrm{CeO}_{2}$ nanoparticles were tested against ESKAPE pathogens (Enterococcus faecium, Staphylococcus aureus, Klebsiella pneumoniae, Acinetobacter baumannii, Pseudomonas aeruginosa, and Enterobacter sp.). Our data revealed that $\mathrm{CeO}_{2}$ nanoparticles at a concentration of $50 \mu \mathrm{g} / \mathrm{mL}$ generated a maximum inhibition zone against all tested pathogens. However, S. aureus, P. aeruginosa, and K. pneumoniae exhibited the higher sensitivity, while E. cloacae, E. faecium, and $A$. baumannii were the least sensitive to $\mathrm{CeO}_{2}$ nanoparticles. In conclusion, our results demonstrate that $\mathrm{CeO}_{2}$ nanoparticles possess an effective antibacterial activity against ESKAPE pathogens and may be used as a potential bionanomaterial for in vivo therapeutic applications.
\end{abstract}

Keywords: ESKAPE pathogens; cerium oxide; antibacterial; nanoparticles

\section{Introduction}

Presently, the progress and spread of drug-resistant microorganisms, as well as their transmissible infections, has become a global challenge [1-3]. In February 2017, to stimulate the research and development of new antibiotic therapies, the world's most well-known health body (WHO) published a list of multidrug-resistant bacteria that can cause severe and deadly infections. The ESKAPE pathogens (Enterococcus faecium, Staphylococcus aureus, Klebsiella pneumoniae, Acinetobacter baumannii, Pseudomonas aeruginosa, and Enterobacter species) were indexed as high priority in the published list [4]. The ESKAPE pathogens represent multidrug-resistant pathogens with a capacity to escape or evade killing by antibiotics [5]. The pathogenic organisms can cause a wide range of infectious diseases in humans, ranging from minor skin infections to major life-threatening infections that include pneumonia, endocarditis, meningitis, surgical infections, septicemia, and toxic shock syndrome [6-8]. 
Gradually, over time, the number of antibiotics used to combat ESKAPE pathogens has declined, while a very few new antibiotics or combinations of antibiotics have been added to the list. Generally, pathogens develop resistance to specific antibiotics for multiple reasons that include: the abuse of antibiotics, the relationship between antibiotic consumption and emergence, resistant genes inherited from genetic materials or acquired from plasmids, horizontal gene transfer (HGT), and natural selection processes $[9,10]$. Indeed, reports have demonstrated that the antimicrobial-resistance (AMR) abilities of these pathogens severely aggravate the ailments of patients hospitalized for chronic diseases, such as cardiovascular diseases, chronic lung infections, diabetes mellitus, arteriosclerosis, chronic obstructive pulmonary disease (COPD), and cancers [11]. These patients may be susceptible to the development of wounds due to the presence of a number of bacterial species forming biofilm and many such chronic wounds are difficult to heal, despite aggressive treatment. Moreover, the AMR ESKAPE pathogens add substantial and unnecessary burdens to the present health care system. In certain conditions, compared to infections that are easily curable with antibiotics, AMR infections cause instability in the healthcare system due to the need for lengthy and expensive treatments, besides prolonging hospital stays [12]. This rising public health emergency has driven the development of innovative antimicrobial therapeutics to treat infections caused by antibiotic-resistant pathogenic microorganisms, particularly those caused by ESKAPE pathogens.

Nanomedicine is an emerging branch of nanotechnology that is increasingly being used to treat the infectious diseases triggered by drug-resistant pathogenic organisms. Over the years, metal nanoparticles have grabbed the attention of many researchers for their use in a wide range of biomedical applications due to their unique physical and chemical properties [13-16]. Amongst nanoparticles, $\mathrm{CeO}_{2}$ synthesized by using different methods is a widely used rare earth element that has shown promising antibacterial activity. $\mathrm{CeO}_{2}$ nanoparticles have gained much attention recently in the context of biomedical applications due to their reactive oxygen species (ROS) scavenging capacity and unique antibacterial activity against both Gram-positive and Gram-negative bacteria $[17,18]$. We have previously reported the antibacterial activity of $\mathrm{CeO}_{2}$ nanoparticles against Escherichia coli using four different sizes of $\mathrm{CeO}_{2}$ nanoparticles and demonstrated that the bactericidal activity of nanoparticles increases with decrease in particle size [14].

In the present study we tested the antimicrobial effects of small-sized $\mathrm{CeO}_{2}$ nanoparticles against ESKAPE pathogens. The antibacterial activity of nanoparticles was determined by using zone of inhibition and minimum inhibition concentrations (MICs) by agar well diffusion and microdilution method, respectively.

\section{Materials and Methods}

\subsection{The Synthesis and Characterization of $\mathrm{CeO}_{2}$ Nanoparticles}

$\mathrm{CeO}_{2}$ nanoparticles were synthesized by a hydrothermal route, as described previously [14]. In brief, $6.8 \mathrm{~g}$ of $\mathrm{Ce}\left(\mathrm{SO}_{4}\right)_{2} \cdot 4 \mathrm{H}_{2} \mathrm{O}$ was dissolved in $35 \mathrm{~mL}$ deionized water, followed by dropwise addition of ammonium solution at room temperature under continuous magnetic stirring. The color of the suspension changed from yellow to brown upon constant addition of ammonia solution. The prepared suspension was transferred into onepot hydrothermal vessels and a reaction process was allowed to occur at $120^{\circ} \mathrm{C}$ for $5-10 \mathrm{~h}$. Upon completion of the reaction process, the hydrothermal vessels were cooled naturally, and precipitates were obtained. The resultant precipitates were washed by centrifugation procedure to eradicate the impurities present. Lastly, the resultant precipitate was dried overnight at $80^{\circ} \mathrm{C}$ to obtain yellowish white color $\mathrm{CeO}_{2}$ nanoparticles. The crystalline nature of $\mathrm{CeO}_{2}$ nanoparticles was examined by XRD (XRD, D8 Discover, Bruker AXS, Karlsruhe, Germany). Raman spectroscopy studies were documented (Micro Raman, Lab Ram HR, Horiba, Japan) in the spectral range of $100-1000 \mathrm{~cm}^{-1}$ with a $514 \mathrm{~nm}$ argon-ion laser. Structural and morphological studies of $\mathrm{CeO}_{2}$ nanoparticles were performed by field emission scanning electron microscopy (FESEM, JSM-7600F-JEOL, Japan). The size, morphology, and crystallinity of the $\mathrm{CeO}_{2}$ nanoparticles were examined by transmission electron mi- 
croscope (TEM, JEM-2100F-JEOL, Japan). High-resolution modes of the equipment were employed to investigate the lattice fringes and d-spacing of the nanoparticles.

\subsection{Microbial Strains}

Enterococcus faecium (E. faecium ATCC 83198), Staphylococcus aureus (S. aureus ATCC 43300), Klebsiella pneumoniae (K. pneumoniae ATCC 13883), Acinetobacter baumannii (A. baumannii ATCC 4414), Pseudomonas aeruginosa (P. aeruginosa ATCC 4406), and Enterobacter cloacae (E. cloacae ATCC 35549) were acquired from Addiriyah Chair for Environmental Studies Lab, Department of Botany and Microbiology, College of Science, King Saud University, Riyadh, Saudi Arabia.

\subsection{Antimicrobial Susceptibility Test}

The antibiotic resistance profile of ESKAPE pathogens was determined by using the Kirby-Bauer disk diffusion method [19]. The Mueller-Hinton broth (MHB) was made and was inoculated with pure colonies of the respective ESKAPE pathogens. The inoculated MHB was kept in an incubator at $37^{\circ} \mathrm{C}$ till the broth culture met the McFarland standard of 0.5. A McFarland 0.5 turbidity standard was equivalent to $1 \times 10^{8} \mathrm{CFU} / \mathrm{mL}$ inoculum. A sterile cotton swab was used to swab each inoculum across the surface of the MuellerHinton agar (MHA) plate. The excess culture was expelled by rolling the swab within the inside wall of the culture tube many times. With forceps, ciprofloxacin (CIP-5 $\mu \mathrm{g})$, amoxicillin/clavulanic acid (AMX-30 $\mu \mathrm{g})$, cefepime (CPM-30 $\mu \mathrm{g})$, ceftaroline (CEF-30 $\mu \mathrm{g})$, gentamycin (GEN-10 $\mu \mathrm{g})$, amikacin (AK- $30 \mu \mathrm{g})$, and imipenem (IPM-10 $\mu \mathrm{g})$ antibiotic disks $6 \mathrm{~mm}$ in diameter were placed on the agar surface, ensuring complete contact with agar plates, and the plates were kept in an incubator for $24 \mathrm{~h}$ at $37^{\circ} \mathrm{C}$. The inhibition zone (diameter) was measured after the incubation period and the results were evaluated according to Clinical and Laboratory Standards Institute criteria guidelines [20].

\subsection{Antibacterial Activity of $\mathrm{CeO}_{2}$ Nanoparticles}

In a preliminary screening, the antimicrobial activity of $\mathrm{CeO}_{2}$ nanoparticles was determined by the agar well diffusion method [21]. In brief, the ESKAPE pathogens were inoculated on the surface of MHA by swabbing. The wells were then filled with varied concentrations of $\mathrm{CeO}_{2}$ nanoparticles $(15,25$, and $50 \mu \mathrm{g} / \mathrm{mL})$ using a sterile cork borer. The positive and negative controls were streptomycin $10 \mu \mathrm{L}$ and DMSO $(10 \%)$, respectively. The plates were kept in an incubator for $24 \mathrm{~h}$ at $37^{\circ} \mathrm{C}$, and after the incubation period the zone of inhibition (diameter) was calculated for each and every pathogen. The inhibitory zone was expressed as the average $(\mathrm{mm})$ produced by the $\mathrm{CeO}_{2}$ nanoparticles in triplicate experiments.

\subsection{Minimum Inhibitory Concentration (MIC) Determination}

The MIC of $\mathrm{CeO}_{2}$ nanoparticles was evaluated in a 96-well microplate using a broth microdilution technique [22]. ESKAPE pathogens were grown overnight on $\mathrm{MHB}$ at $37^{\circ} \mathrm{C}$ and amended using $0.5 \mathrm{McF}$ arland standards to a final density of $1 \times 10^{8} \mathrm{CFU} / \mathrm{mL}$. $\mathrm{CeO}_{2}$ nanoparticles $(1 \mathrm{mg} / \mathrm{mL})$ were dissolved in DMSO and completed with doubling dilutions in the concentration range of 7.8-500 $\mu \mathrm{g} / \mathrm{mL}$. In the 96-well titer plate, each well comprised $90 \mu \mathrm{L}$ of $\mathrm{MH}$ broth in combination with $10 \mu \mathrm{L}$ of culture media and $10 \mu \mathrm{L}$ of different concentrations of $\mathrm{CeO}_{2}$ nanoparticles. The microtiter plate was incubated for $18 \mathrm{~h}$ at $37^{\circ} \mathrm{C}$. The microtiter plate was decoded with a microplate reader at $550 \mathrm{~nm}$ (Synergy HT, BioTek, USA) after incubation, and the lowest concentration of $\mathrm{CeO}_{2}$ nanoparticles that instigated no turbidity was considered as an MIC value. The MIC tests were performed in triplicates to avoid errors.

\subsection{Data Analysis}

Each experiment was performed in triplicate and all the data were statistically analyzed by the IBM SPSS software, version 22.0 (Chicago, IL, USA) and Microsoft Excel 
(version 2016) using one-way analysis of variance (ANOVA). Statistically significant differences were expressed as ${ }^{*} p \leq 0.05,{ }^{* *} p \leq 0.01$, and ${ }^{* * *} p \leq 0.001$.

\section{Results and Discussion}

\subsection{Structural Properties of $\mathrm{CeO}_{2}$ Nanoparticles}

The $\mathrm{CeO}_{2}$ nanoparticles were synthesized by hydrothermal process at a temperature of $120^{\circ} \mathrm{C}$. Figure 1 a shows the $\mathrm{XRD}$ pattern of $\mathrm{CeO}_{2}$ nanoparticles. The diffraction peaks suggest the crystalline nature of $\mathrm{CeO}_{2}$ nanoparticles with a cubic fluorite structure according to JCPDS No. 75-0390. The average crystallite size of $\mathrm{CeO}_{2}$ nanoparticles was calculated from the (111) peak in the XRD patterns using the Scherrer equation: $d=K \lambda \beta \cos \theta$, where $K$ denotes the shape factor, $\lambda$ is the wavelength, $\theta$ is the Bragg diffraction angle, and $\beta$ denotes line broadening at half the maximum intensity (FWHM) of the respective diffraction peaks. The diffraction peaks were detected at $2 \theta=28.478^{\circ}, 32.778^{\circ}, 47.328^{\circ}$, and $56.268^{\circ}$, corresponding to (111), (200), (220), and (311) planes. The XRD results revealed the broadening of peaks and crystallite sizes less than $100 \mathrm{~nm}$, which indicates the fabrication of nanocrystalline $\mathrm{CeO}_{2}$ nanoparticles.
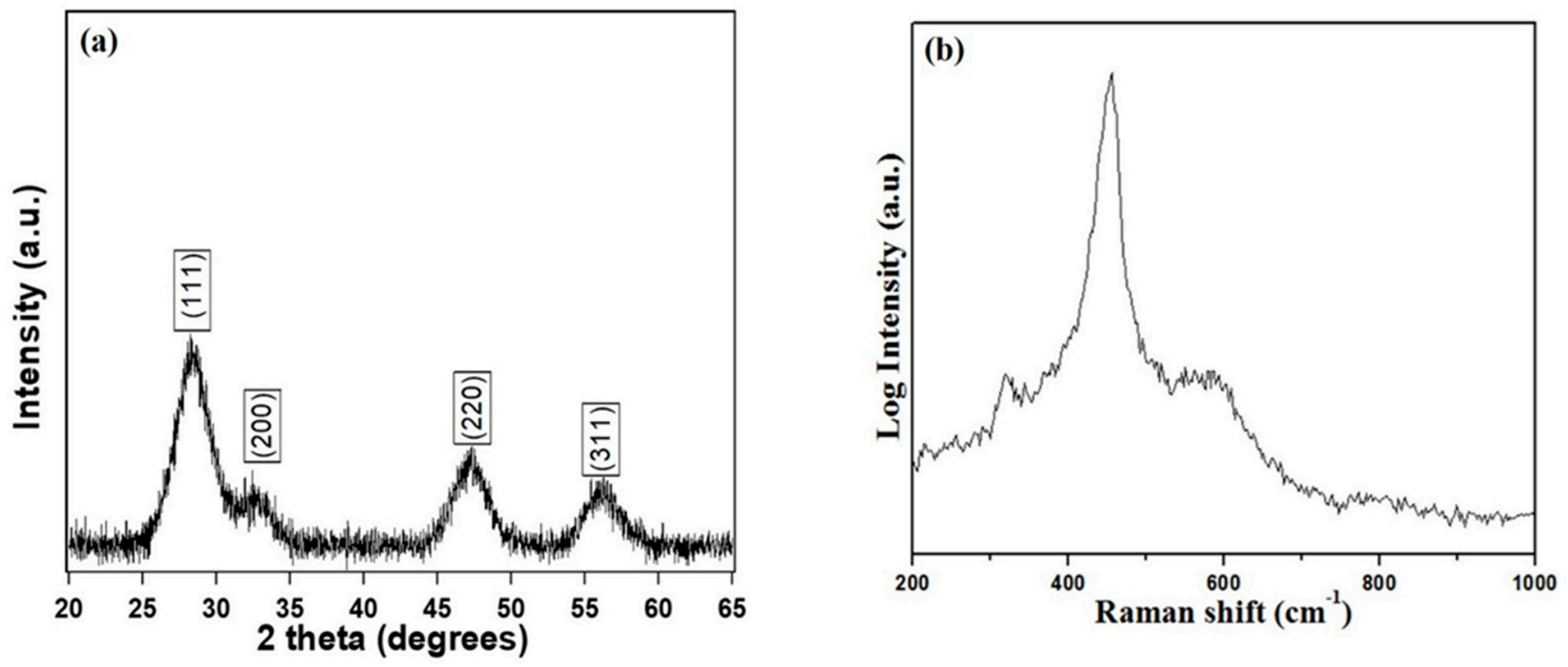

Figure 1. (a) X-ray diffraction pattern and (b) Raman spectra of $\mathrm{CeO}_{2}$ nanoparticles synthesized at $120^{\circ} \mathrm{C}$ reaction processing temperature.

The Raman spectrum of $\mathrm{CeO}_{2}$ nanoparticles is shown in Figure $1 \mathrm{~b}$, which confirmed the formation of pure nanoceria with cubic fluorite structure and oxygen vacancies. The two broad peaks observed in Raman spectra correspond to wavenumbers $464 \mathrm{~cm}^{-1}$ and $572 \mathrm{~cm}^{-1}$, respectively. The band at the lower wavenumber is associated with the Raman active $\mathrm{F}_{2 \mathrm{~g}}$ mode of $\mathrm{CeO}_{2}$, while the $572 \mathrm{~cm}^{-1}$ wavenumber corresponds to the presence of oxygen vacancies in the prepared $\mathrm{CeO}_{2}$ nanoparticles [23].

Figures 2 and 3 show the typical scanning electron microscopy and low- and highresolution transmission electron micrograph images of the $\mathrm{CeO}_{2}$ nanoparticles, respectively. 

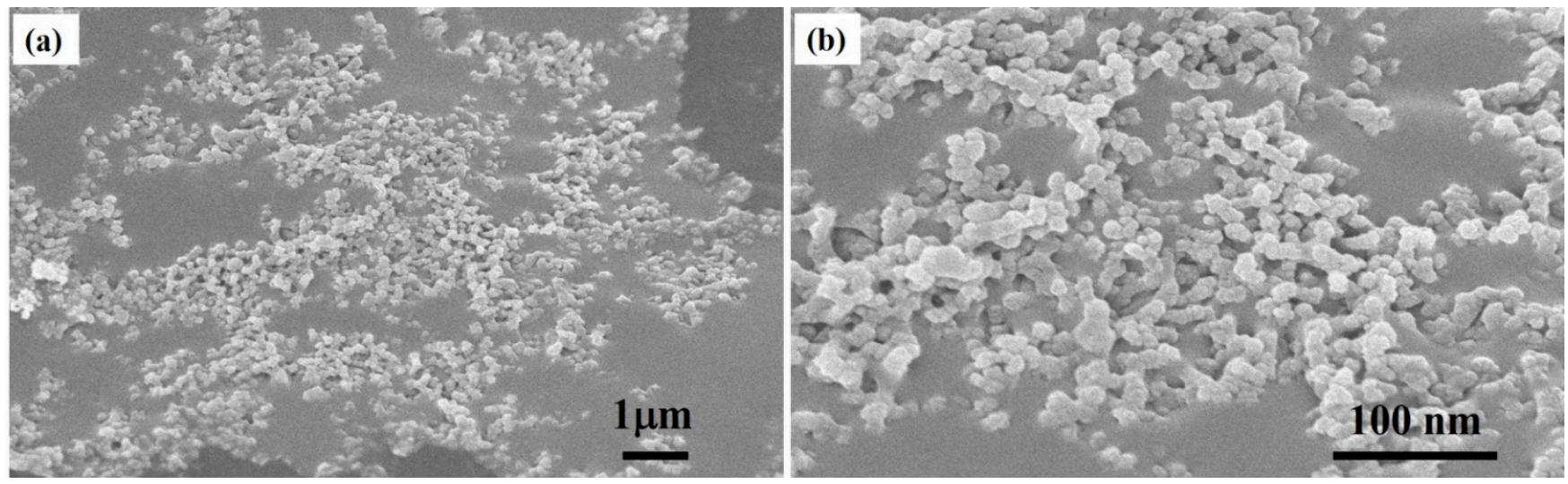

Figure 2. (a) Low-magnification and (b) high-magnification SEM micrographs of the prepared $\mathrm{CeO}_{2}$ nanoparticles.
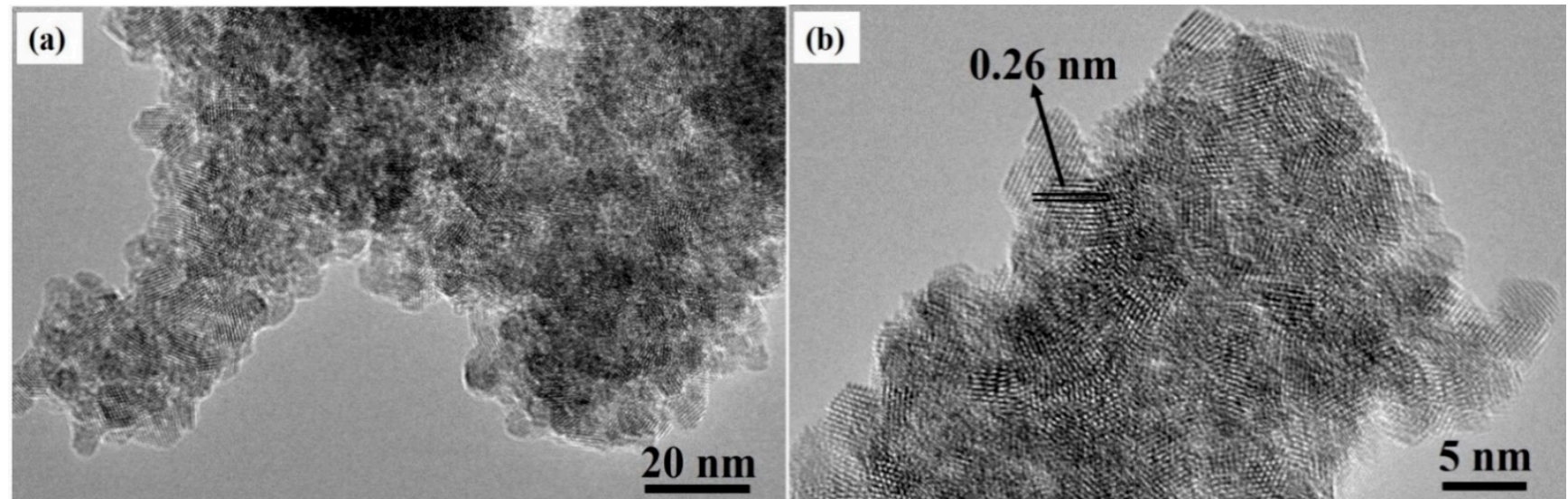

Figure 3. (a) TEM images of $\mathrm{CeO}_{2}$ nanoparticles and (b) HRTEM images of $\mathrm{CeO}_{2}$ nanoparticles.

Figure 2a and $b$ represent the SEM micrographs of $\mathrm{CeO}_{2}$ nanoparticles at lower and higher magnification. The SEM morphological images display the agglomeration of the nanoparticles. These images provide the average size of particle, which is in line with XRD results. The TEM morphological images disclose the uniform $\mathrm{CeO}_{2}$ nanoparticles. The average particle size is obtained by calculating over 100 particles in a random area of the high-resolution TEM image (Figure 3a). The average particle size of $\mathrm{CeO}_{2}$ nanoparticles calculated by TEM was $3.8 \mathrm{~nm}$, which is in good agreement with the XRD results. Figure $3 \mathrm{~b}$ shows the HRTEM images of the $\mathrm{CeO}_{2}$ nanoparticles. The lattice spacing (d) is ca. $0.26 \mathrm{~nm}$, which corresponds to the (111) plane of $\mathrm{CeO}_{2}$ nanoparticles [24].

The mechanism of $\mathrm{CeO}_{2}$ nanoparticles formation was as follows: to begin the process, ammonia solution was added to cerium (IV) salt in a dropwise manner under continuous stirring. The suspension slowly changed its color from yellow to brown by constant addition of ammonia, indicating a change in oxidation state from $\mathrm{Ce}^{3+}$ to $\mathrm{Ce}^{4+}$. The brown suspension was then transferred to a hydrothermal reactor and autoclaved at $120{ }^{\circ} \mathrm{C}$ for $5-10 \mathrm{~h}$. The resulting precipitates were washed and dried at $80^{\circ} \mathrm{C}$ to form yellow white $\mathrm{CeO}_{2}$ powder $[25,26]$.

\subsection{Antimicrobial Susceptibility of ESKAPE Pathogens}

The antibiotic-resistance profiles of ESKAPE pathogens were determined by using seven different antibiotics, including ciprofloxacin, amoxicillin/clavulanic acid, cefepime, ceftaroline, gentamycin, amikacin, and imipenem (Table 1 and Figure 4). Of the antimicrobial agents tested, ciprofloxacin and amoxicillin exhibited $100 \%$ of resistance for all the pathogens. As for the remaining five drugs, cefepime, ceftaroline, gentamycin, amikacin, 
and imipenem were shown to be sensitive, intermediate, and resistant against the tested bacterial pathogens. In general, most of the ESKAPE pathogens showed resistance to the tested drugs. A. baumannii displayed (100\%) resistance against six tested drugs, except imipenem, to which it showed an intermediate sensitivity. On the other hand P. aeruginosa exhibited $(42.85 \%)$ resistance with comparatively more susceptibility against tested antibiotics and E. faecium displayed $(28.57 \%)$ resistance with intermediate sensitivity against gentamycin and amikacin.

Table 1. Antibiotic-resistance profiles of ESKAPE pathogens.

\begin{tabular}{|c|c|c|c|c|c|c|c|}
\hline \multirow[t]{2}{*}{$\mathbf{E P}^{\#}$} & \multicolumn{7}{|c|}{ Antibiotics \$/Inhibition Zone (mm) ${ }^{+}$} \\
\hline & CIP & AMX & CPM & CEF & GEN & AK & IPM \\
\hline Ef & $7.00 \pm 0.3(\mathrm{R})$ & $9.00 \pm 0.2(\mathrm{R})$ & $11.00 \pm 0.4$ & $18.00 \pm 0.1$ & $9.00 \pm 0.1(\mathrm{I})$ & $15.00 \pm 0.1(\mathrm{I})$ & $17.00 \pm 0.5(\mathrm{R})$ \\
\hline Sa & $10.00 \pm 0.5(\mathrm{R})$ & $12.00 \pm 0.2(\mathrm{R})$ & $23.00 \pm 0.4(S)$ & $21.00 \pm 0.5(\mathrm{R})$ & $12.00 \pm 0.5(\mathrm{R})$ & $18.00 \pm 0.5(\mathrm{I})$ & $22.00 \pm 0.6(\mathrm{R})$ \\
\hline $\mathrm{Kp}$ & $11.00 \pm 0.2(\mathrm{R})$ & $13.00 \pm 0.4(\mathrm{R})$ & $17.00 \pm 1.0(\mathrm{R})$ & $22.00 \pm 0.6(S)$ & $22.00 \pm 0.6(S)$ & $12.00 \pm 0.6(\mathrm{R})$ & $15.00 \pm 0.5(\mathrm{R})$ \\
\hline $\mathrm{Ab}$ & $0.0(\mathrm{R})$ & $0.00(\mathrm{R})$ & $9.50 \pm 0.5(\mathrm{R})$ & $15.00 \pm 0.5(\mathrm{R})$ & $15.00 \pm 0.5(\mathrm{R})$ & $13.00 \pm 0.5(\mathrm{R})$ & $19.50 \pm 0.5(\mathrm{I})$ \\
\hline $\mathrm{Pa}$ & $9.00 \pm 0.5(\mathrm{R})$ & $11.00 \pm 0.5(\mathrm{R})$ & $19.00 \pm 0.5(\mathrm{~S})$ & $18.50 \pm 0.5(S)$ & $14.50 \pm 0.5(\mathrm{R})$ & $18.50 \pm 0.5(\mathrm{~S})$ & $16.00 \pm 0.2(\mathrm{R})$ \\
\hline Ec & $10.00 \pm 0.1(\mathrm{R})$ & $12.00+0.5(\mathrm{R})$ & $15.00 \pm 0.4(\mathrm{R})$ & $14.00 \pm 0.2(\mathrm{R})$ & $13.00 \pm 0.2(\mathrm{I})$ & $12.00 \pm 0.2(\mathrm{R})$ & $18.00 \pm 0.5(\mathrm{R})$ \\
\hline
\end{tabular}

\# EP-ESKAPE pathogens, Ef-E. faecium ATCC 51559, Sa-S. aureus ATCC 25904, Kp-K. pneumoniae ATCC 13883, Ab-A. baumanni ATCC 1799, Pa-P. aeruginosa ATCC 10145, Ec-E. cloacae ATCC 35549

\$Antibiotics-ciprofloxacin (CIP-5 $\mu \mathrm{g}$ ), amoxicillin/clavulanic acid (AMX-30 $\mu \mathrm{g}$ ), cefepime (CPM-30 $\mu \mathrm{g}$ ), ceftaroline $(\mathrm{CEF}-30 \mu \mathrm{g})$, gentamycin $(\mathrm{GEN}-10 \mu \mathrm{g})$, amikacin $(\mathrm{AK}-30 \mu \mathrm{g})$, imipenem (IPM-10 $\mu \mathrm{g}) .{ }^{+} \mathrm{R}$ - Resistant, $\mathrm{S}$-Sensitive, I-Intermediate.

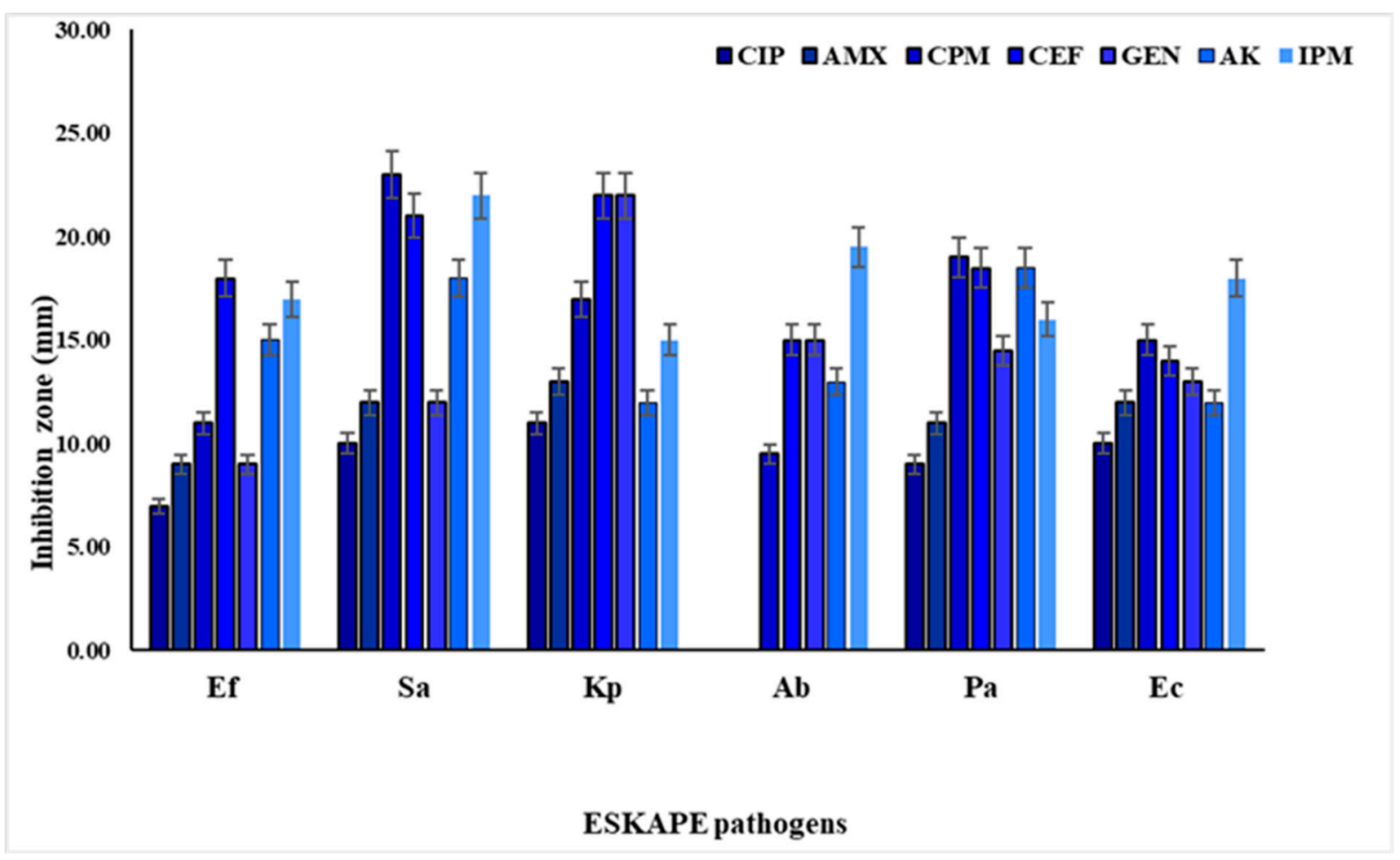

Figure 4. Antibacterial susceptibility pattern of ESKAPE pathogens.

The ESKAPE pathogens have recently been found to have high levels of antibiotic resistance compared to all other clinical pathogens. In Gram-negative ESKAPE infections, resistance to amoxicillin/clavulanic acid and ceftriaxone was the most prevalent resistance pattern, with the exception of $S$. aureus. The majority of $A$. baumannii isolates were resistant to multiple medicines, with over six of the seven antimicrobial agents examined showing resistance to multiple medications. The pathogen $P$. aeruginosa continued to be moderately susceptible to drugs like amikacin, cefepime, and ceftaroline. Overall, ciprofloxacin, amox- 
icillin/clavulanic acid, and imipenem resistance was found to be $85 \%$ among the tested ESKAPE pathogens. These results are supported by a recent study published by Arbune et al. [27], in which they demonstrated the antibiotic resistance of ESKAPE pathogens and reported the highest resistance (nearly $86.6 \%$ ) in $S$. aureus against routine antibiotics.

\subsection{Antibacterial Activity of $\mathrm{CeO}_{2}$ Nanoparticles against the ESKAPE Pathogens}

The antimicrobial potential of $\mathrm{CeO}_{2}$ nanoparticles towards ESKAPE pathogens was examined by the agar well diffusion method. The inhibition zone observed against all tested ESKAPE pathogens was in a range between $22.25 \pm 0.13$ and $7.53 \pm 0.30$ (Table 2 and Figure 5). However, the results showed that $\mathrm{CeO}_{2}$ nanoparticles $(50 \mu \mathrm{g} / \mathrm{mL})$ possessed effective antibacterial activity against ESKAPE pathogens, excluding $A$. baumannii. The $\mathrm{CeO}_{2}$ nanoparticles at $50 \mu \mathrm{g} / \mathrm{mL}$ concentration generated a maximum inhibition zone of $19.40 \pm 0.05 \mathrm{~mm}$ against $S$. aureus, $17.83 \pm 0.21 \mathrm{~mm}$ against $P$. aeruginosa, $17.45 \pm 0.01 \mathrm{~mm}$ against $K$. pneumoniae, $14.90 \pm 0.08 \mathrm{~mm}$ against $E$. cloacae, and $10.92 \pm 0.15 \mathrm{~mm}$ against E. faecium, whereas the zone of inhibition against $A$. baumannii was $8.86 \pm 0.03 \mathrm{~mm}$. Accordingly, the antibacterial efficacy of $\mathrm{CeO}_{2}$ nanoparticles against the tested ESKAPE pathogens was considerable and statistically significant, expect for P. aeruginosa (Table 2).

$\mathrm{CeO}_{2}$ nanoparticles exhibit maximum efficacy because of their small size, allowing a faster adsorption of pathogens compared with bulk nanoparticles. Several mechanisms for the antibacterial activity of metal oxide nanoparticles, particularly $\mathrm{CeO}_{2}$ nanoparticles, have been reported [28-30]. Zhang et al. [31] have described the antibacterial mechanism of $\mathrm{CeO}_{2}$ nanoparticles and factors influencing its antimicrobial mechanisms. The antibacterial activity of $\mathrm{CeO}_{2}$ nanoparticles against microbial pathogens involves either direct interaction with the pathogen or the generation of secondary toxic substances that can cause damage and/or cell death. Previous reports have also stated that $\mathrm{CeO}_{2}$ nanoparticles exhibit effective bactericidal activity due to reactive oxygen species (ROS) generation [31,32].

The antibacterial activity of $\mathrm{CeO}_{2}$ nanoparticles was assessed using the broth microdilution method, and MIC values against ESKAPE pathogens were calculated. Table 3 displays the correspondent MIC values for each ESKAPE bacterial pathogen. The antibacterial potential of $\mathrm{CeO}_{2}$ nanoparticles towards the tested ESKAPE pathogens was comparatively very low MIC value from 15.6 to $125.0 \mu \mathrm{g} / \mathrm{mL}$ except against $A$. baumannii. The MIC values revealed that the inhibitory effect of $\mathrm{CeO}_{2}$ nanoparticles occurred at the lowest concentration $(15.60 \mu \mathrm{g} / \mathrm{mL})$ against $S$. aureus. Thus, overall MIC values were higher than the standard drug streptomycin, and the lowest MIC value was $5.0 \mu \mathrm{g} / \mathrm{mL}$. Taken together, these data reveal that $\mathrm{CeO}_{2}$ nanoparticles hava an effective antibacterial activity against the tested ESKAPE pathogens.

Table 2. Antibacterial activity of $\mathrm{CeO}_{2}$ nanoparticles against ESKAPE pathogens.

\begin{tabular}{|c|c|c|c|c|}
\hline \multirow{2}{*}{$\begin{array}{l}\text { ESKAPE } \\
\text { Pathogens }\end{array}$} & \multicolumn{3}{|c|}{$\begin{array}{c}\text { Concentration of } \mathrm{CeO}_{2}-\mathrm{NPs} \\
(\mu \mathrm{g} / \mathrm{mL})\end{array}$} & \multirow{2}{*}{$\begin{array}{c}\text { Streptomycin } \\
(\mu \mathrm{g} / \mathrm{mL})\end{array}$} \\
\hline & 15 & 25 & 50 & \\
\hline E. faecium ATCC 51559 & $7.53 \pm 0.30^{* * *}$ & $9.25 \pm 0.05^{* * *}$ & $10.92 \pm 0.15^{* * *}$ & $17.83 \pm 0.08$ \\
\hline S. aureus ATCC 25904 & $9.70 \pm 0.40^{* * *}$ & $11.78 \pm 0.15^{* * *}$ & $19.00 \pm 0.40 * *$ & $19.40 \pm 0.05$ \\
\hline K. pneumoniae ATCC 13883 & $10.76 \pm 0.10^{* *}$ & $12.95 \pm 0.13^{* *}$ & $17.45 \pm 0.01 * *$ & $22.25 \pm 0.13$ \\
\hline A. baumannii ATCC 1799 & NIZ $\$$ & NIZ & $8.86 \pm 0.03^{* *}$ & $15.25 \pm 0.12$ \\
\hline P. aeruginosa ATCC 10145 & $8.96 \pm 0.10^{* *}$ & $11.55 \pm 0.13^{* *}$ & $17.83 \pm 0.21 \mathrm{NS}$ & $18.50 \pm 0.50$ \\
\hline E. cloacae ATCC 35549 & $10.45 \pm 0.13^{* * *}$ & $11.95+0.08^{* * *}$ & $14.90 \pm 0.08^{* *}$ & $20.75 \pm 0.13$ \\
\hline
\end{tabular}

$\$$ NIZ-No inhibition zone. (All data represent mean \pm standard deviations of three replicates, and all comparisons are made with streptomycin as the standard drug. ${ }^{* *} p<0.01$, and ${ }^{* * *} p<0.001$. NS-No significant). 


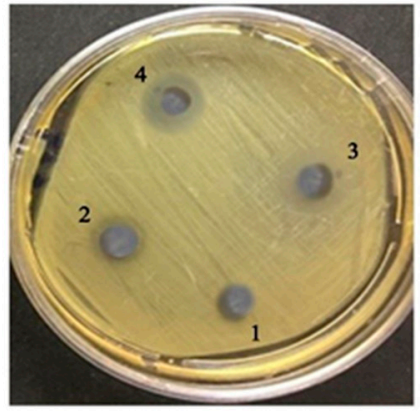

E.faecium ATCC51559

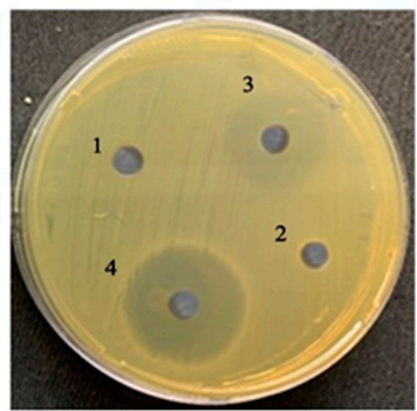

A.baumannii ATCC1799

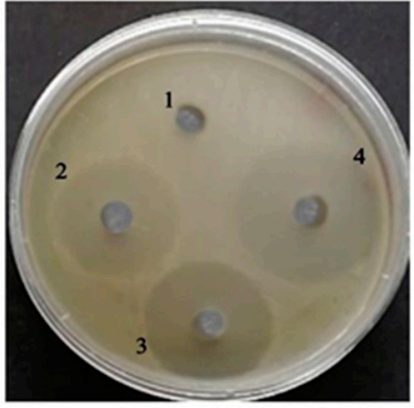

S.aureus ATCC25904

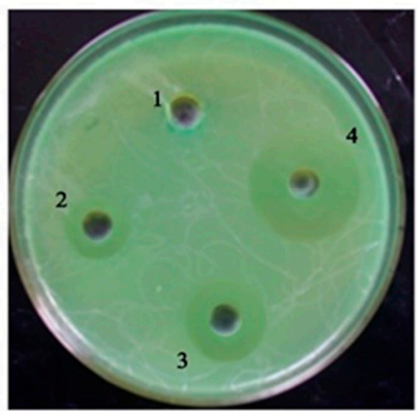

P.aeruginosa ATCC10145

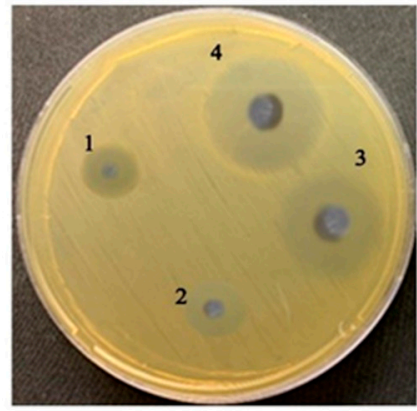

K.pneumoniae ATCC13883

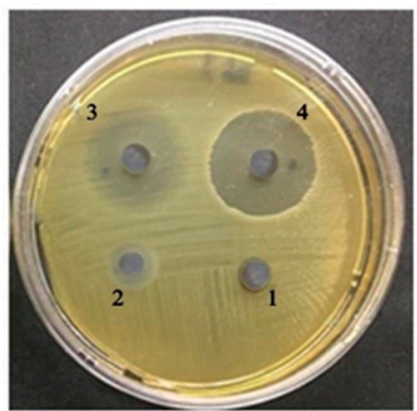

E.cloacae ATCC35549

Figure 5. Antibacterial activities of $\mathrm{CeO}_{2}$ nanoparticles against ESKAPE pathogens using a disk diffusion assay (1-15, 2-25, 3-50 $\mu \mathrm{g} / \mathrm{mL}$ of $\mathrm{CeO}_{2}$ nanoparticles; $4-10 \mu \mathrm{g} / \mathrm{mL}$ streptomycin) standard drug).

Table 3. MIC value of $\mathrm{CeO}_{2}$ nanoparticles against ESKAPE pathogens.

\begin{tabular}{ccc}
\hline \multirow{2}{*}{ ESKAPE Pathogens } & \multicolumn{2}{c}{ MIC $(\mu \mathbf{g} / \mathbf{m L})$} \\
\cline { 2 - 3 } & $\mathbf{C e O}_{\mathbf{2}}$-NPs & Streptomycin \\
\hline E. faecium ATCC 51559 & 125.0 & 10.0 \\
S. aureus ATCC 25904 & 15.6 & 5.0 \\
K. pneumoniae ATCC 13883 & 31.2 & 5.0 \\
A. baumannii ATCC 1799 & 250.0 & 5.0 \\
P. aeruginosa ATCC 10145 & 31.2 & 5.0 \\
E. cloacae ATCC 35549 & 62.5 & 5.0 \\
\hline
\end{tabular}

\section{Conclusions}

Here we report the antibacterial activity of highly pure $\mathrm{CeO}_{2}$ nanoparticles synthesized by a hydrothermal method against the ESKAPE pathogens. The $\mathrm{CeO}_{2}$ nanoparticles purity and fluorite crystal structure were revealed by XRD and Raman analysis. The average diameter calculated by TEM and verified by XRD data was nearly $3.8 \mathrm{~nm}$. The results of this study demonstrate that $\mathrm{CeO}_{2}$ nanoparticles generate a maximum inhibition zone against all pathogens. However, S. aureus, P. aeruginosa, and K. pneumoniae exhibit a higher sensitivity, while E. cloacae, E. faecium, and $A$. baumannii are least sensitive to $\mathrm{CeO}_{2}$ nanoparticles. In conclusion, our study demonstrated that $\mathrm{CeO}_{2}$ nanoparticles possess an effective antibacterial activity against ESKAPE pathogens and may be used as a potential bionanomaterial for in vivo application. However, given the therapeutic potential of $\mathrm{CeO}_{2}$ nanoparticles, further studies are required to elucidate the mechanism of action of these nanoparticles on ESKAPE pathogens. 


\begin{abstract}
Author Contributions: Conceptualization, M.A.D. and R.G.; methodology, M.A.D., R.G. and P.K.; software, M.A.D., R.G. and P.K.; validation, M.A.D., R.G. and P.K.; formal analysis, M.A.D., R.G. and P.K.; investigation, M.A.D., R.G. and P.K.; resources, M.A.D., R.G., P.K., N.A.A.-D. and A.A.A.; data curation, M.A.D., R.G. and P.K.; writing-original draft preparation, M.A.D., R.G. and P.K.; writing-review and editing, M.A.D., R.G., P.K., N.A.A.-D. and A.A.A.; visualization, M.A.D., R.G., P.K., N.A.A.-D. and A.A.A.; supervision, M.A.D. and R.G.; project administration, M.A.D. and R.G.; funding acquisition, M.A.D. and R.G. All authors have read and agreed to the published version of the manuscript.
\end{abstract}

Funding: This project was funded by the National Plan for Science, Technology and Innovation (MAARIFAH), King Abdul-Aziz City for Science and Technology, Kingdom of Saudi Arabia, grant number 14-BIO688-02.

Data Availability Statement: Not applicable.

Acknowledgments: The authors would like to acknowledge the National Plan for Science, Technology and Innovation (MAARIFAH), King Abdul-Aziz City for Science and Technology, Kingdom of Saudi Arabia for funding research grant no. 14-BIO688-02.

Conflicts of Interest: The authors declare no conflict of interest.

\title{
References
}

1. Prestinaci, F.; Pezzotti, P.; Pantosti, A. Antimicrobial resistance: A global multifaceted phenomenon. Pathog. Glob. Health 2015, 109, 309-318. [CrossRef] [PubMed]

2. Abadi, A.T.B.; Rizvanov, A.A.; Haertlé, T.; Blatt, N.L. World Health Organization report: Current crisis of antibiotic resistance. BioNanoScience 2019, 9, 778-788. [CrossRef]

3. Buchy, P.; Ascioglu, S.; Buisson, Y.; Datta, S.; Nissen, M.; Tambyah, P.A.; Vong, S. Impact of vaccines on antimicrobial resistance. Int. J. Infect. Dis. 2020, 90, 188-196. [CrossRef] [PubMed]

4. World Health Organization. Global Priority List of Antibiotic-Resistant Bacteria to Guide Research, Discovery and Development of New Antibiotics. Available online: https://www.who.int/medicines/publications/WHO-PPL-Short_Summary_25Feb-ET_ NM_WHO.pdf (accessed on 15 December 2021).

5. Rice, L.B. Federal funding for the study of antimicrobial resistance in nosocomial pathogens: No ESKAPE. J. Infect. Dis. 2008, 197, 1079-1081. [CrossRef] [PubMed]

6. Mulani, M.S.; Kamble, E.E.; Kumkar, S.N.; Tawre, M.S.; Pardesi, K.R. Emerging strategies to combat ESKAPE pathogens in the era of antimicrobial resistance: A review. Front. Microbiol. 2019, 10, 539. [CrossRef]

7. Santaniello, A.; Sansone, M.; Fioretti, A.; Menna, L.F. Systematic review and meta-analysis of the occurrence of ESKAPE bacteria group in dogs, and the related zoonotic risk in animal-assisted therapy, and in animal-assisted activity in the health context. Int. J. Environ. Res. Public Health 2020, 17, 3278. [CrossRef]

8. Benkő, R.; Gajdács, M.; Matuz, M.; Bodó, G.; Lázár, A.; Hajdú, E.; Papfalvi, E.; Hannauer, P.; Erdélyi, P.; Pető, Z. Prevalence and antibiotic resistance of ESKAPE pathogens isolated in the emergency department of a tertiary care teaching hospital in hungary: A 5-year retrospective survey. Antibiotics 2020, 9, 624. [CrossRef] [PubMed]

9. Read, A.F.; Woods, R.J. Antibiotic resistance management. Evol. Med. Public Health 2014, 2014, 147. [CrossRef]

10. Nature, E. The antibiotic alarm. Nature 2013, 495, 141.

11. Kamaruzzaman, N.F.; Tan, L.P.; Hamdan, R.H.; Choong, S.S.; Wong, W.K.; Gibson, A.J.; Chivu, A.; Pina, M.F. Antimicrobial polymers: The potential replacement of existing antibiotics? Int. J. Mol. Sci. 2019, 20, 2747. [CrossRef]

12. Beyth, N.; Houri-Haddad, Y.; Domb, A.; Khan, W.; Hazan, R. Alternative antimicrobial approach: Nano-antimicrobial materials. Evid. Based Complement. Altern. Med. 2015, 2015, 246012. [CrossRef] [PubMed]

13. Hemeg, H.A. Nanomaterials for alternative antibacterial therapy. Int. J. Nanomed. 2017, 12, 8211. [CrossRef] [PubMed]

14. Dar, M.A.; Gul, R.; Alfadda, A.A.; Karim, M.R.; Kim, D.W.; Cheung, C.L.; Almajid, A.A.; Alharthi, N.; Pulakat, L. Size-dependent effect of nanoceria on their antibacterial activity towards Escherichia coli. Sci. Adv. Mater. 2017, 9, 1248-1253. [CrossRef]

15. Nastyshyn, S.; Raczkowska, J.; Stetsyshyn, Y.; Orzechowska, B.; Bernasik, A.; Shymborska, Y.; Brzychczy-Włoch, M.; Gosiewski, T.; Lishchynskyi, O.; Ohar, H.; et al. Non-cytotoxic, temperature-responsive and antibacterial POEGMA based nanocomposite coatings with silver nanoparticles. RSC Adv. 2020, 10, 10155-10166. [CrossRef]

16. Raczkowska, J.; Stetsyshyn, Y.; Awsiuk, K.; Brzychczy-Włoch, M.; Gosiewski, T.; Jany, B.; Lishchynskyi, O.; Shymborska, Y.; Nastyshyn, S.; Bernasikd, A.; et al. "Command" surfaces with thermo-switchable antibacterial activity. Mater. Sci. Eng. C 2019, 103, 109806. [CrossRef] [PubMed]

17. Thakur, N.; Manna, P.; Das, J. Synthesis and biomedical applications of nanoceria, a redox active nanoparticle. J. Nanobiotechnol. 2019, 17, 84. [CrossRef]

18. Pop, O.L.; Mesaros, A.; Vodnar, D.C.; Suharoschi, R.; Tăbăran, F.; Magerușan, L.; Tódor, I.S.; Diaconeasa, Z.; Balint, A.; Ciontea, L.; et al. Cerium oxide nanoparticles and their efficient antibacterial application in vitro against gram-positive and gram-negative pathogens. Nanomaterials 2020, 10, 1614. [CrossRef] 
19. Kirby, B. Kirby-Bauer disk diffusion susceptibility test protocol. Am. Soc. Microbiol. 2009, 66, 208.

20. Clinical and Laboratory Standards Institute (CLSI). Performance Standards for Antimicrobial Susceptibility Testing, 30th ed.; CLSI Supplement M100; Clinical and Laboratory Standards Institute: Wayne, PA, USA, 2020.

21. Clinical and Laboratory Standards Institute (CLSI). Methods for Antimicrobial Susceptibility Testeding of Anaerobic bacteria, 9th ed.; CLSI standard M11; Clinical and Laboratory Standards Institute: Wayne, PA, USA, 2018.

22. Al-Bayati, F.A.; Al-Mola, H.F. Antibacterial and antifungal activities of different parts of Tribulus terrestris L. growing in Iraq. J. Zhejiang Univ. Sci. B 2008, 9, 154-159. [CrossRef]

23. McBride, J.R.; Hass, K.C.; Poindexter, B.D.; Weber, W.H. Raman and x-ray studies of Ce1-x RE x O2-y, where RE = La, Pr, Nd, Eu, Gd, and Tb. J. Appl. Phy. 1994, 76, 2435-2441. [CrossRef]

24. Bharathi, R.N.; Sankar, S. Investigation of transport properties of Pr doped cerium oxide nanoparticles as a solid electrolyte for IT-SOFC applications. J. Inorg. Organomet. Polym. 2018, 28, 1829-1838. [CrossRef]

25. Wu, N.-C.; Shi, E.-W.; Zheng, Y.-Q.; Li, W.-J. Effect of pH of medium on hydrothermal synthesis of nanocrystalline cerium(IV) oxide powders. J. Am. Ceram. Soc. 2002, 85, 2462-2468. [CrossRef]

26. Xu, J.; Li, G.; Li, L. CeO2 nanocrystals: Seed-mediated synthesis and size control. Mater. Res. Bull. 2008, 43, 990-995. [CrossRef]

27. Arbune, M.; Gurau, G.; Niculet, E.; Iancu, A.V.; Lupasteanu, G.; Fotea, S.; Vasile, M.C.; Tatu, A.L. Prevalence of antibiotic resistance of ESKAPE pathogens over five years in an infectious diseases hospital from South-East of Romania. Infect. Drug Resist. 2021, 14, 2369. [CrossRef]

28. Kannan, S.K.; Sundrarajan, M. A green approach for the synthesis of a cerium oxide nanoparticle: Characterization and antibacterial activity. Int. J. Nanosci. 2014, 13, 1450018. [CrossRef]

29. Arumugam, A.; Karthikeyan, C.; Hameed, A.S.H.; Gopinath, K.; Gowri, S.; Karthika, V. Synthesis of cerium oxide nanoparticles using Gloriosa superba L. leaf extract and their structural, optical and antibacterial properties. Mater. Sci. Eng. C 2015, 49, 408-415. [CrossRef]

30. Yadav, L.R.; Manjunath, K.; Archana, B.; Madhu, C.; Naika, H.R.; Nagabhushana, H.; Nagaraju, G. Fruit juice extract mediated synthesis of $\mathrm{CeO} 2$ nanoparticles for antibacterial and photocatalytic activities. Eur. Phys. J. Plus. 2016, 131, 154. [CrossRef]

31. Zhang, M.; Zhang, C.; Zhai, X.; Luo, F.; Du, Y.; Yan, C. Antibacterial mechanism and activity of cerium oxide nanoparticles. Sci. China Mater. 2019, 62, 1727-1739. [CrossRef]

32. Farias, I.A.P.; Santos, C.C.L.D.; Sampaio, F.C. Antimicrobial activity of cerium oxide nanoparticles on opportunistic microorganisms: A systematic review. BioMed Res. Int. 2018, 2018, 1923606. [CrossRef] 